\title{
As orações de Mansata e a farsa do poder
}

\author{
Francesca Rayner
}

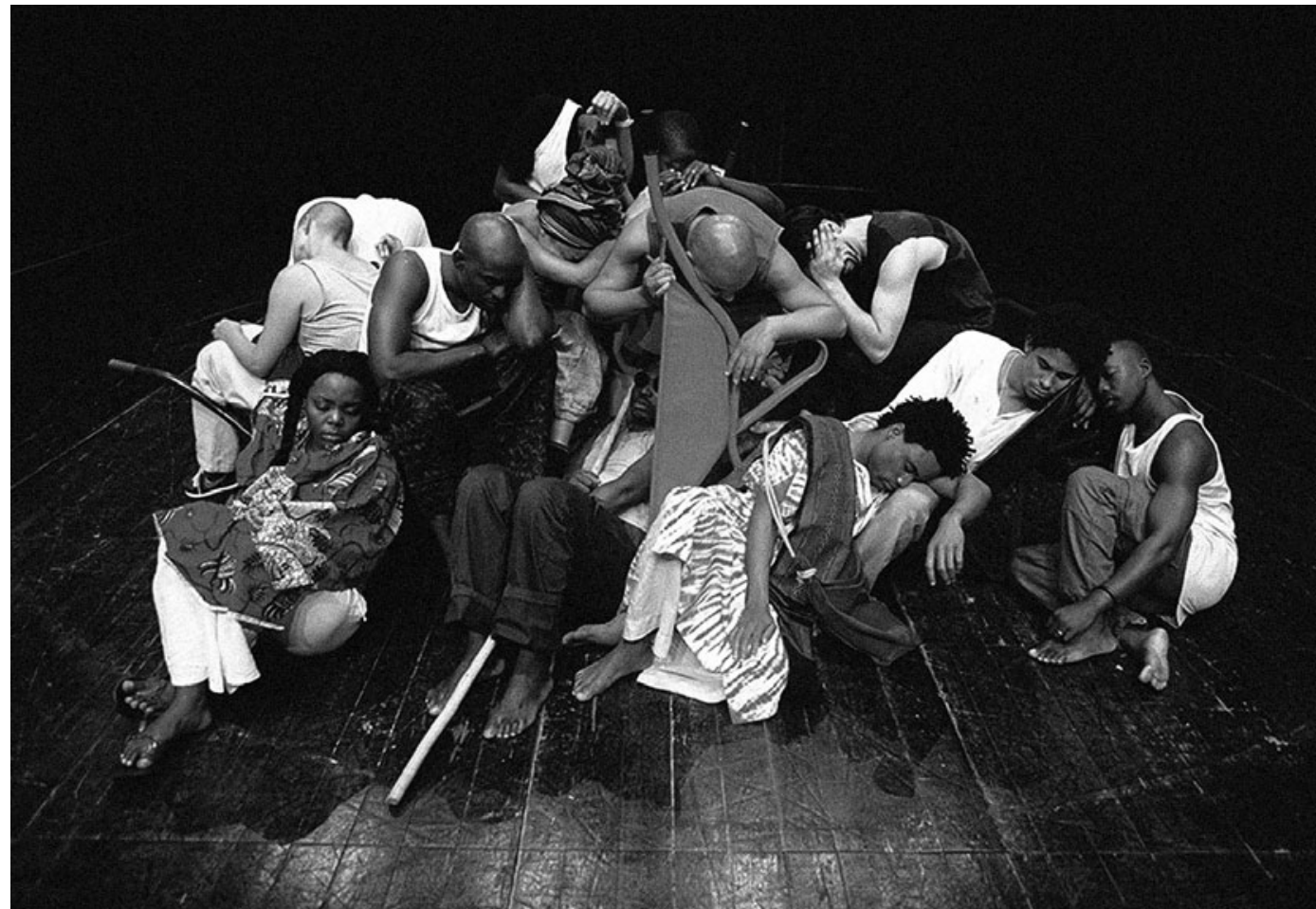

As orações de Mansata de Abdulai Sila,

enc. António Augusto Barros, Cena Lusófona, 2014 (início do

espectáculo: [em cima, da esquerda para a direita] Solange Sá, Rogério Boane [de costas], Paulo Figueira, Elane Nascimento, Wilson de Sousa, Amador Fernandes, Miguel Magalhães, Igor Lebreaud; [em baixo, da esquerda para a direita] Marleny Musa, Jorge Biague, Emilio Lucombo, Ridson Reis, Trindade Gomes da Costa), fot. Augusto Baptista.

Certas experiências teatrais recordam-nos porque é que continuamos a fazer e a ver teatro, e a representação d' As orações de Mansata de Abdulai Sila, em Bissau, foi uma dessas experiências. Foi o segundo de dois espetáculos no pais natal do autor, e circulou numa digressão internacional incluindo apresentações em Portugal, Espanha e Angola. 0 Centro Cultural Francês em Bissau, onde se apresentaram os espetáculos, estava

completamente lotado, obrigando alguns espectadores a sentarem-se nas escadas do auditório. 0 facto de ser apresentado no Centro Cultural Francês revela a falta de espaços qualificados em Bissau para este tipo de projecto teatral e uma falta de investimento na Guiné por parte dos decisores políticos. No entanto, espera-se que o sucesso desta iniciativa leve a uma reconsideração do valor cultural e político de espetáculos como este por parte também da representação portuguesa em Bissau.

Com várias obras de ficção já editadas, As orações de Mansata é o primeiro texto dramático de Abdulai Sila a ser publicado na Guiné-Bissau. No entanto, isto não deve obscurecer o facto de a própria Guiné-Bissau ter uma história longa e rica de tradições performativas menos baseadas em texto e mais na canção, dança e comédia, com uma forte componente física. De facto, foi a inclusão destas tradições na representação d' As orações de Mansata, uma adaptação de Macbeth de William Shakespeare ao contexto da Guiné-Bissau, que conferiu maior interesse e valor a este espetáculo. Confirma-se que as preocupações de Shakespeare com o poder e a corrupção, tal como são representadas neste espectáculo, não serão estranhas à atormentada história política e social da Guiné-Bissau. E ganharam um valor maior num espetáculo em que o texto, o movimento e a música criaram imagens impressionantes da vida individual e colectiva na Guiné-Bissau pós-colonial. Aliás, o facto de o espetáculo reunir performers de Portugal, Brasil, Angola, S. Tomé e Príncipe e Moçambique alargou a sua crítica aos mecanismos do poder noutros contextos pós-coloniais e trabalhou no sentido de uma noção especificamente lusófona dos prazeres e potenciais perigos do espetáculo intercultural.

Enquanto que a primeira noite atraiu principalmente diplomatas e agentes culturais, com José Ramos Horta em representação da equipa local das Nações Unidas, o realizador Flora Gomes e o próprio Abdulai Sila em
Francesca Rayner

é Professora Auxiliar na Universidade do Minho onde lecciona unidades curriculares da graduação e pósgraduação em Teatro Artes Performativas e onde é Directora da Licenciatura em Teatro. A sua investigação incide sobre a representação de 
representação da elite cultural de Bissau, a segunda noite reuniu um público mais diversificado entre os quais muitos homens e mulheres jovens. Também estiveram presentes os participantes do workshop de interpretação realizado um ano antes, numa louvável demonstração de solidariedade com os dois atores da Guiné-Bissau que foram mais tarde escolhidos para participarem no espetáculo. 0 workshop tinha sido organizado pela Cena Lusófona, sediada em Coimbra, que também organizou a digressão e publicou a peça na sua coleção de textos dramáticos lusófonos. Neste sentido, foi notável como muitos membros do público compraram não só o programa do espetáculo, mas também o próprio texto, e alguns deles podiam ser vistos a ler a peça antes da entrada em cena dos atores, confirmando assim a expetativa em torno do que iria ser apresentado.

0 espetáculo começou com uma abertura assinalável, que foi (re)citada com redobrada relevância já no seu final. Assim que o palco se iluminou, todos os performers estavam amontoados dentro ou em torno dos característicos carrinhos-de-mão usados em Bissau para transportar todo o tipo de materiais. 0 facto de a carga, neste caso, ser constituída por pessoas em vez de produtos, e de o público não ter a certeza se os performers em cena estavam a dormir ou mortos, funcionou como uma estranha premonição do que estava para vir. Foi nesta altura que o quadro inicial ganhou vida, tornando-se numa vibrante cena de rua de Bissau com individuos e pequenos grupos a cruzarem caminhos e trocarem cumprimentos ou recriminações. Depois desta cena, o clima mudou de novo em duas cenas onde um individuo foi abordado, inicialmente por três homens e depois por três mulheres, atribuindo-Ihe poderes que parecia desconhecer. Na segunda destas cenas, um homem passou a correr e partiu um dos potes de barro que as mulheres tinham deixado à beira da estrada. 0 foco no simbolismo do número três e a predição do poder atribuído a um individuo impreparado relembra o encontro entre Macbeth e as três bruxas, mas, nesta adaptação contemporânea, as ligações entre o poder espiritual e temporal foram desenvolvidas de uma forma mais extensiva, e a vontade dos seis em atribuirem poderes a um individuo contra a sua vontade foram localizados num contexto político onde a crença em individuos heróicos, que podem ser os salvadores da nação, tende a produzir líderes ditatoriais. Quanto ao homem que partiu o pote de barro, Amambarka (Rogério Boane), ele é a figura de Macbeth na peça, a pessoa que conspira para tirar do poder o anterior Chefe Supremo, Mwankeh (Paulo Figueira), tornando-se depois vitima de uma conspiração semelhante por parte dos seus antigos aliados. Esta ênfase na circularidade do poder, com base numa série de conspirações e contraconspirações, significa que não restou nenhuma figura heróica no fim do espetáculo, e, apesar das suas constantes afirmações de que os fins justificam os meios, todas as personagens tinham sangue nas mãos. Numa cena particularmente poderosa, os fantasmas, daqueles que Amambarka torturou ou matou para chegar ao poder, regressaram para o assombrar com corpos destruidos, mãos ensanguentadas e histórias de amizades traídas.

Nesta dura dissecação do poder, houve no entanto vários momentos de humor refinado. Quando Mwankeh chamou os seus conselheiros para uma reunião, o facto de entre eles se incluírem elementos para tchumul-tchamal (confusão e desordem) ou meker-meker (intriga) indicava a inversão de prioridades dos governantes, enquanto a recusa destes conselheiros em assumir a responsabilidade pelo mais pequeno incidente demonstrava a ineficácia dos responsáveis chefes. Tal ineficácia foi reforçada em palco através de um arquivo de papel constantemente pontapeado pelo chão - de conselheiro para conselheiro - e, depois, por um movimento coletivo em que eles, vestidos de fato e gravata, se viravam para revelar pernas e nádegas nuas. Esta sobreposição de comédia física e verbal contagiou também duas cenas subsequentes que ilustravam a forma como os votos de lealdade são facilmente quebrados quando emerge um novo líder. Na primeira destas cenas, Nkungha (Trindade Gomes da Costa) a denunciou Amambarka a Mwankeh como sendo um diabo que o tinha forçado a conspirar para retirar Mwankeh do poder. No preciso momento em que demonstrava esta coerção física, Amambarka e os seus conspiradores entram e assassinam Mwankeh, forçando Nkungha a um volteface e jurando uma nova e longa lealdade a Amambarka. No entanto, Amambarka é ele próprio assassinado pelos seus antigos apoiantes - Yem-Yem (Ridson Reis) e Djibisappoh (Wilson de Sousa) - mas após Yem-Yem ter matado Djibisappoh, um Amambarka moribundo levantase para assassinar Yem-Yem. A última palavra do espetáculo, proferida por Amambarka, foi "zero", uma profunda condenação dos resultados concretos das guerras e lutas internas pelo poder como sendo devastadores para a nação e para o povo que os líderes dizem representar. 0 quadro inicial com os carrinhos-de-mão foi então 


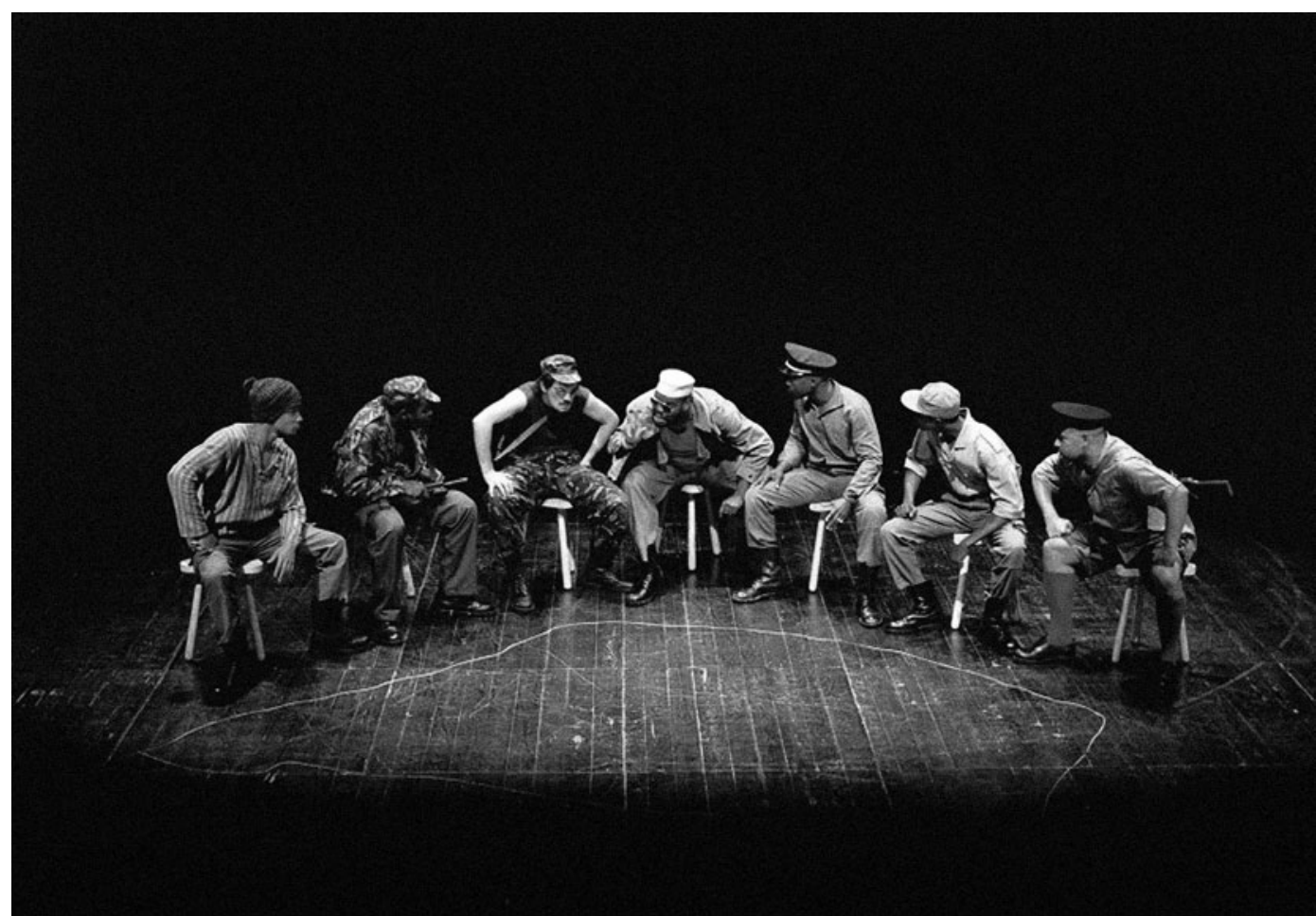

As orações de Mansata, de Abdulai Sila, enc. António Augusto Barros, Cena Lusófona, 2014 (conspiração dos ministros: [da esquerda para a direita] Ridson Reis, Jorge Biague, Igor Lebreaud, Rogério Boane Trindade, Wilson de Sousa e Miguel Magalhães, fot. Augusto Baptista. repetido no final do espetáculo, mas desta vez as personagens pareciam mais visivelmente mortas do que adormecidas pelo que a noção de uma tragédia nacional emergiu de uma forma mais clara.

Embora a maioria dos papéis da peça fosse para atores, Amambarka tinha também três esposas, neste espetáculo interpretadas por uma actriz angolana, uma actriz portuguesa e outra actriz brasileira (Marleny Musa, Solange Sá e Elane Nascimento). Tal como Lady Macbeth na peça de Shakespeare, podemos ver que estas mulheres têm uma forte influência sobre Amambarka. Elas incentivamno a retomar o poder que perdeu dentro da elite governante, incitando-o a agir como "um homem a sério" e recordando-Ihe que o afecto, que elas Ihe dedicam, se baseia na capacidade de as sustentar financeiramente, provando, assim, que também elas são seduzidas pelo poder. A multiplicação da figura de Lady Macbeth introduz a questão poligâmica da Guiné-Bissau, e a inclusão de três atrizes de diferentes contextos nacionais ilustra a forma produtiva na qual tradições teatrais variadas interagem neste espetáculo. Os diferentes sotaques do português mantiveram-se distintos mas, ao mesmo tempo, combinaram-se harmoniosamente, e os performers com formação em teatro físico colaboraram de forma natural com performers com formação mais referida à proferição de um texto. Havia, na verdade, bastantes evidências da troca de saberes das diferentes tradições cénicas entre os artistas que participarem neste espetáculo. Destacava-se uma interpretação assombrosa da actriz angolana com uma canção sobre os efeitos da guerra, que foi depois retomada por outros em palco, e por várias vezes movimentos de dança eram coordenados entre todos os performers. Da mesma forma, as duas cenas com Nkungha podiam ter sido inteiramente baseadas na fisicalidade, mas foi-Ihes conferido um humor extra pelo rigor com que o texto da peça foi dito. Os três atores, que interpretavam os conselheiros espirituais (Igor Lebraud,
Jorge Biague e Emilio Lucombo), criaram em cena uma imagem coerente de autoridade apesar de - ou talvez justamente por - virem de três culturas nacionais diferentes. No entanto, os dois intérpretes da Guiné-Bissau, um dos quais interpretou um dos conselheiros espirituais (Jorge Biague) e o outro Nkungha, foram particularmente apreciados pelo público de Bissau. Durante o espetáculo, ouviram-se muitos comentários vindos da plateia, que variaram entre o riso de reconhecimento - o reconhecimento do que se sabe mas que não pode ser dito - e a convergência paradoxal de admiração e reprovação relativamente à figura de Amambarka, em muito devido à excelente interpretação de Rogério Boane neste papel.

Com um simples mas eficaz desenho de luz e um cenário de madeira criado especialmente por carpinteiros locais para este espetáculo e que podia ser rapidamente adaptado de uma forma eficaz para as diferentes cenas, o espetáculo tinha como componentes mais expressivas o texto de Abdulai Sila, com uma forte carga política e o trabalho dos atores.

Foi, certamente, um dos melhores espetáculos a que assisti este ano, mesmo sem levar em conta o esforço enorme em criar e levar o espetáculo a diferentes paises. No entanto, enquanto que o espetáculo em Bissau não podia ter corrido melhor, a tragédia dramática da peça deu lugar a uma maior tragédia da vida real na última semana da digressão quando a Ministra da Cultura angolana proibiu as representações em Luanda três horas antes da entrada em cena dos atores. A suposta razão para a proibição foi a falta de segurança do edifício onde o espetáculo ia ser apresentado, mas considerando que foi ali realizada uma programação durante todo o ano, e que a Ministra tinha conhecimento prévio do espetáculo e das suas intenções, a proibição foi provavelmente imputável a questões de segurança do Governo Angolano. Ironicamente, portanto, a representação dramática do poder, não isenta de aspetos paradoxalmente ligados à 
farsa, deu lugar a um episódio que mantém em aberto as ambiguidades e eventuais receios do poder político.

Muito provavelmente a proibição deveu-se à força acrescida do espetáculo comparativamente com o texto impresso, porque embora o Governo Angolano tenha consentido a circulação do texto no seu país, os espetáculos iriam, certamente, atrair um público mais vasto e diversificado que testemunharia e reagiria a esta exposição da farsa no exercício do poder
Fica aqui registada a inquietação perante uma proibição que nos parece inaceitável, esperando que tenha consequências na reivindicação de liberdade na criação e circulação de práticas artísticas. Além disso, e apesar da referência a este incidente nos jornais portugueses, não houve qualquer reprovação ou comentário por parte daqueles que trabalham e que têm responsabilidades nas artes cénicas em Portugal.

Nota final para a identificação do espetáculo:

Título: As orações de Mansata Autor: Abdulai Sila. Dramaturgia e encenação:António Augusto Barros. Interpretação: Amador Fernandes, Elane Nascimento, Emilio Lucombo, Igor Lebreaud, Jorge Biague, Marleny Musa, Miguel Magalhães, Paulo Figueira, Ridson Reis, Rogério Boane, Solange Sá, Trindade Gomes da Costa, Wilson de Sousa (Pepelinho) Cenografia: João Mendes Ribeiro/Luísa Bebiano. Figurinos, adereços e imagem gráfica:Ana Rosa Assunção. Direcção musical e banda sonora: Jarbas Bittencourt. Movimento: Zebrinha. Desenho de luz: Fernando Conceição. Kora:Braima Galissa. Video:Andrzej Kowalski. Técnica de Máscara/commedia dell'arte: Filipe Crawford. Capoeira:Professor Flajola. Assistência de encenação: Igor Lebreaud/Sofia Lobo. Assistência de direcção musical: Ridson Reis. Operação de luz e vídeo: Rui Valente. Operação de som: José Diogo. Direcção de montagem:Rui Valente. Produção: Eduardo Pinto, Pedro Rodrigues, Rui Valente, Sofia Lobo. Direcção de cena:Miguel Magalhães. Construção de cenário:Carlos Figueiredo, Paulo Santos, Rui Valente. Execução de adereços:Cubos Activos (Tori), GPOD/Gonçalo Prudêncio Ofice for Design, Ana Rosa Assunção, Maria João Robalo, Joana Amado, Rui Valente. Execução de figurinos: Maria do Céu Simões. Montagem: José Diogo, Rui Valente. Fotografia:Augusto Baptista. Fotografia de ensaios: Eduardo Pinto, Sofia Lobo. Promoção e divulgação:Pedro Rodrigues, Eduardo Pinto. Consultor de magia: Luís Rodrigues. Cabelos: Carlos Gago/llídio Design. Estagiária de produção (Estudos Artísticos): Joana Amado. Local e data de estreia: Teatro da Cerca de São Bernardo, Coimbra, 17 de Outubro de 2013. 